\title{
THE ISPS CODE AND IT'S IMPLEMENTATION IN MALAYSIA
}

\author{
Nurul Huda Ahmad Razali \& Wan Siti Adibah Wan Dahalan
}

The Faculty of Law, Universiti Kebangsaan Malaysia

Email: wsa@ukm.my

Tel: 0389216381, Faks: 0389253217

\begin{abstract}
The International Ship and Port Facility Security (ISPS) Code was introduced by International Maritime Organization (IMO) on December 2002. The purpose is to enhance maritime security by outlining minimum security standards for ships and port facilities and also to establish an international framework for cooperation in efficiently collecting and sharing information to detect security threats such terrorism and to take preventive actions. Malaysia had ratified the ISPS Code on 2003 and the ISPS Code was enforced worldwide on 2004. Several problems were encountered at the beginning stage of the ISPS Code implementation. Thus, this article examines the implementation of ISPS Code in Malaysia and its implications. The implementation of ISPS Code has given positive implications by increasing security level of ships and port facilities in Malaysia. The ISPC Code imposes strict requirement of the certificate of the ship, better control of port facility, and restricts unauthorised access to ship and port facilities area. The implementation of the ISPS Code should be emulated worldwide.
\end{abstract}

Keywords: ISPS Code, Ship, Port

\section{Introduction}

The ISPS Code was introduced on December 2002 by International Maritime Organization (IMO) after September 11, 2001 event on the World Trade Centre in New York. This code is an amendment to the Safety of Life at Sea (SOLAS) Convention and includes in new Chapter XI-2 of SOLAS. It consists of two parts. Part $\mathrm{A}$ is mandatory and Part B is recommendatory. Part $\mathrm{A}$ is concerned with contract on the government responsibility for the setting of security level, declaration of security, obligation of shipping companies, ship security, ship security assessment, company and ship security officer, port facility security and etc. Part B takes into account post implementation of Chapter XI-2 of SOLAS and provisions of Part A, as Part B is only recommendatory in nature.

Generally, ISPS Code prescribes responsibilities to governments, shipping companies, shipboard personnel, and port or facility personnel

www.imo.org.com

See Regulation 2(1) of Chapter XI-2 SOLAS

John King, The Security of Merchant Shipping, Cardiff University UK, Marine Policy 29, 2005 to "detect security threats and take preventative measures against security incidents affecting ships or port facilities used in international trade ${ }^{1}$. Moreover, it is also the maritime leg of the supply chain, namely port and shipping that is most at risk from terrorism related threats. This Code applies both on passenger ships and cargo ships including tankers of 500 gross tonnages or more as well as port facilities serving ships on international voyages, and mobile offshore units. ${ }^{2}$

Firstly, the objective of ISPS Code is to establish an international framework involving cooperation between contracting government, government agencies, local administrations and the shipping and port industries. Secondly, ISPS Code is to detect security threats and take preventive measures against security incidents affecting ships or port in international trade. Thirdly, to ensure confidence that adequate and proportionate maritime security measures are in place. ${ }^{3}$ Thus, in really practice of the code, it comprises checks prior to entry of a ship into a port, as well as certif- 
icate verification in the port. ${ }^{4}$

Before the emergence of ISPS Code, the world was facing many maritime threats especially on ship and port activities. The hijacking of the ACHILLE LAURO in October 1985 and the suicide attack on USS COLE has alerted the world to the terrorist threat to ship. Seventeen of the COLE crew were killed and while 39 of them were wounded. Meanwhile, on October 2002, the French Tanker LIMBURG was attacked by terrorists in Yemen. This article is therefore discusses the implementation of ISPS Code in Malaysia and its implications.

\section{THE IMPLEMENTATION OF ISPS CODE}

In implementing ISPS Code, an obligations affecting contracting government, designated authority, ports officer, companies and ships are provided for a standardized, consistent framework for managing risk and permitting the meaningful exchange and evaluation information ${ }^{5}$. In Malaysia, the contracting government responsible in implementing ISPS Code is fall under the jurisdiction of the Ministry of Transport (MOT).

This Ministry held to set security levels applicable at any particular time with regard to ships flying and approaching their ports within their territory, ${ }^{6}$ and to issue appropriate instruction and provide security related information when the Security Level is raised to 3 (High Level).

Furthermore, this Ministry is also responsible to designate an authority through the government mechanism to be responsible for ensuring the implementation of the provisions in the ISPS Code pertaining to port facility security and ship or port interface, from the point of view of the port facility.

Thus although the Ministry of Transport is the contracting government that is responsible to implement ISPS Code, however it also involves security issues under the National Security Council (NSC), an agency under the Prime Minis- ters Department also came into the picture. This is because the National Security Council (NSC) has the authority to mobilize security forces such as the Royal Malaysian Navy, Malaysian Maritime Enforcement Agencies, Royal Marine Police, and the Immigration Department if there is a need to do so. Based on this, it was also agreed that the National Security Council (NSC) shall be responsible in determining the security level in consultation with the Malaysian Marine Department (MARDEP), which is the designated authority responsible for the implementation of the ISPS.7

The designated authority, the Malaysian Marine Department (MARDEP), is responsible to approve the Port Facility Security Assessment (PFSA) and subsequent amendments to an approved assessment. Moreover this department is also responsible to determine the port facilities which will be required to designate a Port Facility Security Officer (PFSO), to approve the Port Facility Security Plan (PFSP) and subsequent amendments to an approved plan. MARDEP is also responsible in exercising control in compliance measures and testing approved plans or its amendment. ${ }^{8}$ As the ISPS Code is securing of port area there must be an appointment of Port Area Security Officer who is responsible to facilitate the development, implementation review and maintenance of a Port Area Security Plan and also to liaise with Port Facility Security Officer to facilitate administration and improve communication.

Whereby the Port Facility Security Officer is responsible to conduct initial security survey of the port facility in order to develop, maintain, implement and exercise the Port Facility Security Plan. Other responsibilities include undertaking security inspections of the port facility and ensuring the continuation of appropriate security measures. The Port Security Officer also recommends and incorporates changes to improve the Port Facility Security Plan, enhances security awareness to the port facility personnel and ensures adequate training for the port ${ }^{9}$.

4 See Regulation 9 of Chapter XI-2 of SOLAS

5 Hartmut Hesse and Nicholas L.Charalambous, New Security Measures for the International Shipping Community, WMU Journal of Maritime Affairs, 3 (2004).

6 See Regulations 3 of Chapter XI-2 SOLAS

7 Nor Apandi Osnin, ISPS Code: Implementation in Malaysia, Lloyd's MIU Handbook of Maritime Security, Edited by Rupert HerbertBurns, Sam Bateman and Peter Lehr, Auerbach Publication, Taylor \& Francis Group, 2009

8 Nor Apandi Osnin, ISPS Code: Implementation in Malaysia, Lloyd’s MIU Handbook of Maritime Security, Edited by Rupert HerbertBurns, Sam Bateman and Peter Lehr, Auerbach Publication, Taylor \& Francis Group, 2009

9 ISPS Code, 2003 Edition, International Ship and Port Facility Security Code and SOLAS Amendment 2002, International Maritime 
Commitments from various parties are crucial for the successful implementation of ISPS Code. This includes contracting government, designated authority, and ship and port facilities. At the first, Malaysia faced some problems, such as the cost of implementing the code. The Organization for Economic Co-operation and Development (OECD) estimated that the initial cost on global ship operators to comply with the ISPS Code amounted to at least USD 1.279 billion and USD 730 million per year thereafter. For Malaysian ship owners, who have spent a substantial amount of money and effort to obtain the International Ship Security Certificate (ISSC), another round of problems begin, with ports and contracting government implementing differing port state control measures. Malaysian ports and port authorities too will be busy carrying out their obligations under the Code. In addition, preparation should also be allocated for visits from the US Coast Guard under the US Coast Guards International Port Security Program. ${ }^{10}$

Another problem is the need for the Port Facility Security Officer, Ship Security Officer and the related staff to undergo for vigorous training on the operation of the ISPS Code11. For an example, after the enforcement of the ISPS Code worldwide in July 1, 2004, Malaysia shipping companies were slow to implement the code as the costs were high especially in appointing the Company Security Officer, Ship Security Officer, Ship Security Plan, and Ship Security Assessment.

Increasing the security by ISPS Code states could led to major source of shipping delays (Banamyong, 2005). Local shipping delays specifically impact port efficiency. Furthermore, the inverse relationship between efficiency and costs is interrelated. It is important to achieve high levels of both security and efficiency at costs that can be managed and controlled (Kwek \& Goswami, 2004).

The fear of black listing of port for security in the mind of developing countries is another concern (Banomyong, 2005).

\section{SECURITY LEVEL}

The ISPS Code sets the security levels at any particular time and it is the responsibility of the Contracting Government (Ministry of Transport) to apply this code to ships and port facilities. This security level is important for port or ship safety condition. There are three security levels for international use, firstly, the Level 1 which is normal. In Level 1, the minimum position protective security measures are to be maintained at all times. Secondly, Level 2, which is the heightened risk. In Level 2, an additional protective security measures shall be maintained for a period of time as a result of heightened risk of security incident. Thirdly, Level 3, which is exceptional risk. In Level 3, a further specific protective security measures shall be maintained for a limited period of time. It happens when a security incident is probable or imminent, although it may not be possible to identify the specific target. ${ }^{12}$

\section{REQUIREMENT OF SHIP AND PORT FACILITY IN ISPS CODE}

\section{SHIP}

The ISPS Code embodied through a number of minimum functional security requirements for ships and port facilities. Meanwhile, ships are subjected to verification and certification. They have to bear an International Ship Security Certificate (ISSC), indicating compliance with the requirements of the mandatory provisions of the ISPS Code. $^{13}$

The shipping companies operating ships are required to prepare Ship Security Plan (SSP). Ship Security Plan (SSP) is established under the responsibility of the Company Security Officer (CSO) which provides inter alia for the minimum operational and physical security measures the ship under security level 1 at all times. ${ }^{14}$

\footnotetext{
Organization (IMO).

10 Syahriman Baharom Shah, MIMA Issue Paper, Security Maritime Trade: Post-September 11 Maritime Security Initiatives and their Implications on Malaysia, , 2004, Maritime Institute of Malaysia (MIMA).

11 www.mima.com.my

12 Hartmut Hesse and Nicholas L.Charalambous, New Security Measures for the International Shipping Community, WMU Journal of Maritime Affairs, 3 (2004).

13 See Article 19 of Part A of ISPS Code
}

14 
Meanwhile, a Company Security Officer $(\mathrm{CSO})^{15}$ as the representative of the company has to conduct Ship Security Assessment (SSA). From this assessment, Ship Security Plan (SSP) will be drawn up and to be submitted for approval. The Recognized Security Organization (RSO) is then would approve the Ship Security Plan (SSP) and Ship Security Assessment (SSA).

The International Ship Security Certificate (ISSC) is then issued to the ship after Ship Security Assessment (SSA) and Ship Security Plan (SSP) have been approved by Recognized Security Organization (RSO). This certificate is only valid for five year. After the five year period shipping companies have to follow the same procedures as stipulated in the ISPS Code. Meanwhile, the shipping companies have to appoint a Ship Security Officer (SSO) ${ }^{16}$ in their ships who is then responsible in implementing Ship Security Plan (SSP) on board of the ship.

Besides implementing Ship Security Plan (SSP), the Ship Security Officer is also responsible to the Ship Security Alert System (SSAS). This alert system is prescribed to the seafarers in order for Ship Security Officer (SSO) to be able to notify authorities and other ships or vessels of the terrorist activities on board of the ships. ${ }^{17}$

Ship Security Officer (SSO) holds responsibility to communicate with the Port Facilities Security Officer at the port facility. SSO is required to communicate certain information such as whether the ship is in possession of a valid ISSC, the last port of call, and the security level of the ship. Similarly, SSO can communicate with the Company Security Officer (CSO) to obtain any pertinent information relevant to the port the ship is going to call at ${ }^{18}$. This entire requirement must be followed in order for the code to be implemented successfully. Commitment from all of the officers and their co operations are necessary.

\section{PORT FACILITY}

The ISPS Code requires minimum requirement from the port facilities. Port Facility Security Plan (PFSP) should be drawn in compliance with
ISPS Code. But before PFSP can be drawn, Port Facility Security Assessment (PFSA) should be conducted and need to be reviewed periodically. The Port Facility Security Assessment (PFSA) and Port Facility Security Plan (PFSP) have to be approved by Designated Authority. PFSA is used to determine which Port Facilities are required to appoint Port Facility Security Officer (PFSO).

Meanwhile, Port Facility Security Officer (PFSO) is responsible for the preparation of the Port Facility Security Plan (PFSP). Like the Ship Security Plan, the Port Facility Security Plan shall indicate the minimum operational and physical security measures the Port Facility shall take at all times in security Level 1 . The plan should also indicate the additional, or intensified, security measures the Port Facility can take to move to security level 2. Furthermore the plan should indicate the possible preparatory actions the Port Facility could take to allow prompt response to the instructions that may be issued by the authorities responding at security level 3 to a security incident or threat.

The Port Facility Security Officer also needs to ensure that the Port Facility Security Plan provisions are implemented and monitored on the continuing effectiveness and relevance of the approved plan, including commissioning independent internal audits of the application of the plan. The Port Facility Security Assessment covering the Port Facility also needs to be reviewed. The reviewed of assessment may lead to amendments to the approved plan ${ }^{19}$. Major amendments will have to be submitted to the Designated Authority for re-approval.

\section{PORTS IN MALAYSIA}

Ports in Malaysia can be classified as federal ports and state ports. Apart from these major ports, there are other minor ports and landing places that come under the purview of the Malaysian Marine Department (MARDEP). The federal ports, which are under the jurisdiction of the Ministry of Transport, are further divided into major and minor ports. There are at present seven major 
federal ports consisting of Port Klang, Penang Port, Bintulu Port, Johor Port, Pasir Gudang Port, Pelabuhan Tanjung Pelepas, Kuantan Port, and Kemaman Port. Out of seven federal ports, six of them except Kemaman Port have been privatized.

These privatized ports are regulated by port authorities. Apart from the ports mentioned earlier, there are additional minor ports and jetties under the control of the Malaysian Marine Department (MARDEP), making a total of 78 Port Facility. Out of these 78 Port Facilities, 71 are listed as being in compliance with the ISPS Code ${ }^{20}$.

\section{IMPLICATIONS OF ISPS CODE TO MALAYSIA}

There are positive implications of ISPS Code to Malaysia. The new security initiatives have had some positive impacts to ships and ports in Malaysia. A good relation has been developed among contracting governments (Ministry of Transport), designated authority (MARDEP), ships officer and port officer, when they cooperate together to detect and deter acts which threaten security in the maritime transport $^{21}$ sector in Malaysia. The training and heightening awareness of security have also promoted good relationships between the shipping lines and also the ports.

The implementation of the code has reduced the vulnerability of the industry to such terrorist attack, thus countering threat and reducing the risk.

Furthermore, by this code there is enhancement of security level of ships and port facilities in Malaysia. By putting in place an effective and complaint security regime, ports will be able to continue to participate fully in global trade, and the potential economic consequences of a major security breach, which might result in disruption or even port closure ${ }^{22}$, are serious indeed. The ISPS Code also provides security measures and at the same time can save costs in the long term, as better security will reduce incidents of terrorist, thefts and smuggling and can support the call for reduction of insurance premiums, resulting in reduced transportation costs.

\section{CONCLUSION}

As a conclusion the implementation of ISPS Code in Malaysia has shown positive impacts in enhancing the maritime security, especially on ship and port facilities in Malaysia. The implementation of ISPS Code also enhances national and international security. Meanwhile, mutual cooperation and communication can be strengthening between contracting government, designated authority, ship and port officer. Besides that, the strict requirement of the ISPS Code by the Port Facility Security Officer and also Ship Security Officer could provide important information to authorities on the condition of both port and ships. Thus the security level guided by ISPS Code can be the first information on the condition of port and ship, and thus prompted the relevant authorities to take any preventive action. While the emergence of ISPS Code has come out in response to threats of terrorism, its goal to detect and deterrence of threats to ships and ports can provide security measures at international level and also national level, especially in Malaysia.

\footnotetext{
20 Nor Apandi Osnin, ISPS Code: Implementation in Malaysia, Lloyd’s MIU Handbook of Maritime Security, Edited by Rupert HerbertBurns, Sam Bateman and Peter Lehr, Auerbach Publication, Taylor \& Francis Group, 2009 


\section{REFERENCES}

Nor Apandi Osnin, ISPS Code: Implementation in Malaysia, Lloyd's MIU Handbook of Maritime Security, Edited by Rupert HerbertBurns, Sam Bateman and Peter Lehr, Auerbach Publication, Taylor \& Francis Group, 2009

Syahriman Baharom Shah, MIMA Issue Paper, Securing Maritime Trade: Post-September 11 Maritime Security Initiatives and their Implications on Malaysia, 2004.

Chris Trelawny, Maritime Security: Implementation of ISPS Code, $3^{\text {rd }}$ Intermodal, Africa, 2005.

Bernard Delsupexhe, French Ministry of Transport and Equipment France, Practical Implementation of the ISPS Code in the French Seaports.
IMO News, The Magazine of the IMO Issue 3, 2010

Hartmut Hesse and Nicholas L.Charalambous, New Security Measures for the International Shipping Community, WMU Journal of Maritime Affairs, 3 (2004).

Chris Trelawny, IMO Maritime Security Policy, Background Paper.

The American Journal of International Law, Volume 100. No 1. Jan 2006 pp 222-224

ISPS Code, 2003 Edition, International Ship and Port Facility Security Code and SOLAS Amendment 2002, International Maritime Organization (IMO).

www.imo.org.com

www.mima.com.my 